\title{
Franck MERCIER, Isabelle ROSÉ (éds.), Aux marges de l'hérésie. Inventions, formes et usages polémiques de l'accusation d'hérésie au Moyen Âge
}

Rennes, Presses Universitaires de Rennes, coll. « Histoire », 2017, 378 p.

Bénédicte Sère

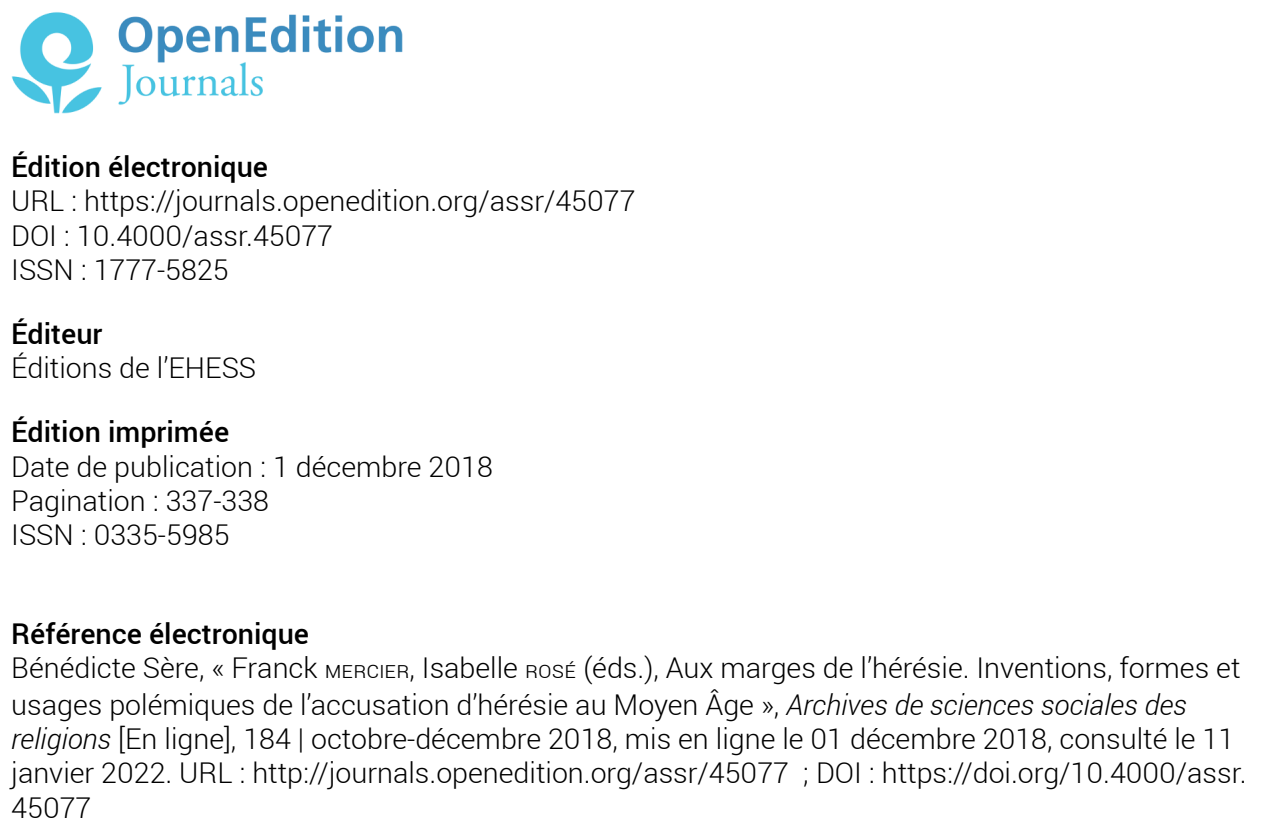

Ce document a été généré automatiquement le 11 janvier 2022.

(C) Archives de sciences sociales des religions 


\title{
Franck MERCIER, Isabelle ROSÉ (éds.), Aux marges de l'hérésie. Inventions, formes et usages polémiques de l'accusation d'hérésie au Moyen Âge
}

Rennes, Presses Universitaires de Rennes, coll. « Histoire », 2017, 378 p.

\author{
Bénédicte Sère
}

\section{RÉFÉRENCE}

Franck MERCIER, Isabelle RosÉ (éds.), Aux marges de l'hérésie. Inventions, formes et usages polémiques de l'accusation d'hérésie au Moyen Âge, Rennes, Presses Universitaires de Rennes, coll. « Histoire », 2017, 378 p.

Sans conteste, les études hérésiologiques sont florissantes. Beaucoup, pourtant, a déjà été écrit. Comment alors prétendre à nouveau publier sur le thème ? C'est que ce souschamp historiographique qu'est le domaine de l'hérésiologie a ceci en propre qu'il se renouvelle en s'accélérant, toujours dynamique, rarement irénique. Aussi convient-il de replacer le présent volume, fruit de trois journées d'études ces dernières années à l'université de Rennes II en lien avec le GIS HéPoS (Hérésie, pouvoirs et sociétés - Antiquité, Moyen Âge, Époque moderne) dans le courant de révision historiographique depuis une vingtaine d'années. Le temps de Montaillou - le célèbre ouvrage de Le Roy Ladurie - est passé, où l'historien, lui-même en réaction au discours officiel d'une histoire religieuse traditionnelle, entendait rendre leur voix aux hérétiques, vaincus de l'histoire et marginaux par là même sympathiques. De manière copernicienne, les années 1980 ont renversé l'approche : désormais, la « société de persécution » (R. I. Moore, 1987, trad. fr. 1991) met en question l'existence même des hérétiques. La dissidence est plutôt appréhendée comme une réalité artificielle construite par le discours normatif. L'hérésie, loin d'être une forme objectivable de la dissidence, est «inventée » (M. 
Zerner, 1998) par la centralité d'un discours clérical visant à " exclure " pour mieux " ordonner» la société chrétienne elle-même (D. Iogna-Prat, 1998). L'hérésie ne préexiste donc pas à sa définition par l'Église, et ce, malgré les réactions passionnelles d'une faction de l'historiographie face à cette révision, réactions traduites dans l'affrontement des vocables eux-mêmes, tels que celui d'«albigéisme», produit de l'écclésiologie centralisatrice (J.-L. Biget), contre celui du « catharisme », lequel prétend être reconnu comme une "vraie » hérésie (A. Brenon, P. Jimenez). Le ressort piégé des études hérésiologiques reste la plasticité du concept d'hérésie: protéiforme, polysémique, labile, la définition de l'hérésie est difficilement saisissable. Pour André Vauchez, en 2014, c'est l'anticléricalisme qui reste le fond commun de toutes les dissidences ; pour Christine Caldwell Ames, en 2015, dans son essai comparatiste des trois monothéismes, c'est l'altérité inassimilable qui est à l'origine du concept. Quoi qu'il en soit, les jeunes médiévistes du présent volume, sous la direction de Franck Mercier et d'Isabelle Rosé, entendent, dans une série de onze contributions à l'érudition éblouissante, appréhender l'hérésie, loin de toute essentialisme, en insistant sur la plasticité du concept. La force de leur option heuristique est précisément d'utiliser l'insaisissabilité du concept pour mieux l'approcher. Par-delà la fixité de la sémantique, la récurrence des effets rhétoriques, la permanente des métaphores ou encore la canonicité des références souvent patristiques, l'hérésie ne s'approche jamais mieux que dans ses accusations. Elle ne se saisit que par ce qui la dénonce. Or, ce sont justement ces accusations qui se dilatent au fil des siècles et au gré des espaces géographiques, juridiques et sociaux. Relèvent de l'accusation d'hérésie les champs du paganisme (V. Toneatto), du judaïsme (V. Toneatto), de l'usure (Cl. Lenoble), du trafic des charges ecclésiastiques (I. Rosé), du fondamentalisme évangélique (U. Brunn), voire du goût pour la philosophie païenne (A. Trivellone), du gibelinisme (F. Mazel, S. Parent), ou encore de l'opposition au pouvoir royal (B. Dumézil), de toute forme de rébellion au pouvoir princier (F. Mercier), de la sorcellerie ou de l'astrologie (M. Ostorero). À la manière dont le vocable de pesta au Moyen Âge recouvre une multitude de phénomènes bactériologiques et épidémiologiques (S. Thrupp), haeresia ou haereticus se découvre comme une catégorie générique dont le statut de crime englobant dit assez l'origine de l'énonciation: le pouvoir central et sa volonté d'imposer un régime chrétien de vérité. L'accusation d'hérésie est donc bien une arme polémique dont le lien avec le pouvoir est intrinsèque, comme l'a encore récemment montré une étude anglosaxonne de 2014, intitulée Religion, Power and Resistance from the $\mathrm{XIt}^{\text {h }}$ to the $\mathrm{XVI}^{\text {th }}$ Centuries : Playing the Heresy Card (éd. K. Bollermann, Th. M. Izbicki \& C. Nederman), qui évoque toutes les voies par lesquelles l'accusation d'hérésie, une " carte à jouer ", peut être employée à des fins politiques.

2 La dilatation du concept d'hérésie, outre les champs qu'elle investit, est également pensée comme une dilatation dans le temps long, par rapport à la chronologie de l'historiographie traditionnelle. Le Moyen Âge est envisagé dans son ensemble avec une nouvelle proposition de chronologie, qui remet en cause la «lente mise en place de la société de persécution ", chère à R. I. Moore (voire la contribution d'E. Bain dans le volume). En effet, trois moments sont dégagés : une séquence patristique, fondatrice des topiques antihérétiques, qui s'enchaîne sur le tournant majeur de Grégoire le Grand, moment d'appropriation de l'hérésie par le monopole pontifical. Un deuxième moment, plus classiquement connu, pourrait se définir par l'assimilation de l'hérésie à la lèse-majesté ( $\mathrm{XI}^{\mathrm{e}}$-XII ${ }^{\mathrm{e}}$ siècles). L'accusation d'hérésie s'étend ainsi aux laïcs c'est-à-dire désormais que c'est l'ensemble de la société qui est potentiellement suspecte d'hérésie. 
Enfin, les $\mathrm{XIII}^{\mathrm{e}}$ et $\mathrm{XV}^{\mathrm{e}}$ siècles assistent à l'extension de l'hérésie en direction de la sorcellerie, à moins que la sorcellerie - en affinité avec la trahison politique - ne soit plus un nouveau visage de l'hérésie mais finalement son dépassement, lorsque l'État plus que la papauté assume sa poursuite et sa sanction. Lors même que la prise en charge de l'hérésie se sécularise et devient une affaire d'État, l'acception de la dissidence ne change pas de forme : elle reste une modalité de l'anticonformisme et une posture de résistance face au pouvoir, dans sa constitutive spécularité par rapport à l'autorité. La question d'une "fin de l'hérésie » est alors posée, en finale du volume, dans la très belle conclusion d'Isabelle Rosé : "Et si la fin de l'hérésie résultait en définitive de son appropriation par l'État, de même que celui-ci, comme le suggère l'historien italien Paolo Prodi, a absorbé l'Église ? Alors, fin de l'hérésie ou plutôt ultime mutation (sur le mode de la sécularisation) du crime contre la foi?» Suggestif questionnement qui pourtant ne prend pas en compte - comme ne le prend pas en compte l'ensemble du volume d'ailleurs - les hérésies des Wyclif et Jean Huss qui saturent le $\mathrm{xv}^{\mathrm{e}}$ siècle et le transcendent, les dissidences des Pauvres Spirituels, matrice d'un discours hérésiologique fort, les constructions discursives autour de l'« hérésie du conciliarisme " par le premier de ses censeurs, Juan de Torquemada, pour une longue postérité, la confessionnalisation de l'accusation d'hérésie au moment du Schisme protestant, les stigmatisations topiques contre les libertins des $\mathrm{XVI}^{\mathrm{e}}$ puis $\mathrm{XVII}^{\mathrm{e}}$ siècles, etc. Peut-être faudrait-il alors poser la question autrement : peut-il y avoir une fin de l'hérésie? Si l'hérésie est bien constitutive de l'orthodoxie en un effet spéculaire, dont la nécessité était déjà proclamée par saint Paul (I Cor. 11, 19), si l'hérésie autorise la définition identitaire du discours dominant, si l'hérésie n'existe que par rapport à une orthodoxie qui en a décidé, si encore le dominium énonce, lui-même et lui seul, la dissidence pour mieux imposer son régime de vérité et sa normativité, comment alors penser une fin de l'hérésie sauf à imaginer - utopiquement - qu'il y ait une fin du dominium? 